\title{
Reduced Anxiety and Depression-Like Behaviors in Mice Lacking GABA Transporter Subtype I
}

\author{
Guo-Xiang Liu' ${ }^{1,2}$, Guo-Qiang Cai', You-Qing Cai ${ }^{1,2,3}$, Zhe-Jin Sheng', Jie Jiang', Zhengtong Mei', Zhu-Gang \\ Wang $^{3,4}$, Lihe Guo' and Jian Fei*, 1,3,4 \\ 'Laboratory of Molecular Cell Biology, Institute of Biochemistry and Cell Biology, Model Organism Research Center, Shanghai Institutes for \\ Biological Sciences, Chinese Academy of Sciences, Shanghai, China; ${ }^{2}$ Graduate School of Chinese Academy of Sciences, Beijing, China; ${ }^{3}$ Shanghai \\ Nan Fang Model Organism Research Center, Pu Dong, Shanghai, China; ${ }^{4}$ Model Organism Division, E-institutes of Shanghai Universities, \\ Shanghai Jiao Tong University, Shanghai, China
}

\begin{abstract}
$\gamma$-Aminobutyric acid (GABA) transporter subtype I (GATI), which transports extracellular GABA into presynaptic neurons, plays an important regulatory role in the function of GABAergic systems. However, the contributions of the GATI in regulating mental status are not fully understood. In this paper, we observed the behavioral alterations of GATI knockout $\left(\mathrm{GATI}^{-1-}\right)$ mice using several depressionand anxiety-related models (eg, the forced-swimming test and the tail-suspension test for testing depression-related behaviors; the openfield test, the dark-light exploration test, the emergence test, and the elevated plus maze (EPM) test for anxiety-related behaviors). Here we found that $\mathrm{GATI}^{-1-}$ mice showed a lower level of depression- and anxiety-like behaviors in comparison to wild-type mice. Furthermore, $\mathrm{GATI}^{-1-}$ mice exhibited measurable insensitivity to selected antidepressants and anxiolytics such as fluoxetine, amitriptyline, buspirone, diazepam, and tiagabine in the tail-suspension test and/or the EPM test. Moreover, the basal level of corticosterone was found to be significantly lower in $\mathrm{GATI}^{-1-}$ mice. These results showed that the absence of GATI affects mental status through enhancing the GABAergic system, as well as modifying the serotonergic system and the hypothalamic-pituitary-adrenal (HPA) activity in mice.

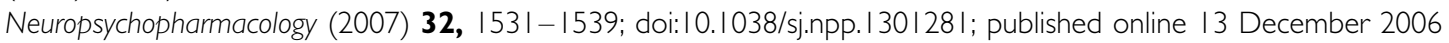

Keywords: GABA transporter I; depression; anxiety; knockout mouse

\section{INTRODUCTION}

Depression and anxiety affect millions of people of different ages, races, religions, and income. However, the molecular basis for the development of these disorders remains largely unknown. Increasing evidence suggests that the $\gamma$-aminobutyric acid (GABA) system is important in the pathogenesis of psychological disease, including anxiety and depression. Studies employing magnetic resonance spectroscopy suggest that unipolar depression is associated with reductions in cortical GABA levels. Antidepressant and mood-stabilizing treatments also appear to raise cortical GABA levels and ameliorate GABA deficits in patients with mood disorders (Krystal et al, 2002). GABA receptors, including $\mathrm{GABA}_{\mathrm{A}}$ receptors and $\mathrm{GABA}_{\mathrm{B}}$ receptors, have been generally considered as the targets for treatment of

\footnotetext{
*Correspondence: Dr J Fei, Laboratory of Molecular Cell Biology, Institute of Biochemistry and Cell Biology, Model Organism Research Center, Shanghai Institutes for Biological Sciences, Chinese Academy of Sciences, No 7 Building, 319 Yue Yang Road, Shanghai 20003I, China, Tel: + 8621 54920376, Fax: + 86215895 I 005, E-mail: jfei@sibs.ac.cn Received 30 March 2006; revised 29 September 2006; accepted 2 October 2006
}

mental illness (Kalueff and Nutt, 1996). However, drugs used for such treatment have side effects (Johnston, 1996; Tsang and Xue, 2004). Animal studies with GABA uptake inhibitors demonstrated marked anxiolytic-like effects, implying that modulating GABA uptake could be a possible target for the treatment of mental disorders (Sayin et al, 1992; Schmitt and Hiemke, 1999).

GABA transporters (GATs), located on the plasma membrane of cells, are key molecules in GABAergic transmission. Through reuptake of released GABA, GATs control the duration and intensity of GABAergic activity at the synapse (Borden, 1996; Radian et al, 1990). Molecular cloning studies have identified multiple GABA transporter subtypes, including GAT1, GAT2, GAT3, and GAT4. GAT1 is the major subtype present at both synaptic and extrasynaptic sites in the brain (Chiu et al, 2002; Guastella et al, 1990). Our previous work had demonstrated that the GAT1 gene knockout mice have decreased ethanol aversion and ethanol reward, and insensitivity to both the sedative/ hypnotic and the motor stimulant effects of ethanol (Cai et al, 2006). It was also reported that GAT1 deficiency leads to enhanced extracellular GABA levels and results in an overactivation of $\mathrm{GABA}_{\mathrm{A}}$ receptors (Jensen et al, 2003). 
Behavioral tests showed that GAT1-deficiency causes tremor, ataxia, and nervousness (Chiu et al, 2005). Nevertheless, there is little direct evidence to show the role of GAT1 in the pathogenesis of depression and anxiety. In our present study, we employed six behavioral tasks that are sensitive to clinically efficacious antidepressants or anxiolytics to investigate anxiety- and depression-like behaviors of the GAT1 gene knockout mice. These behavioral tasks include tail-suspension test, forced swim test, open-field test, dark-light exploration test, emergence test, and elevated plus maze (EPM) (Borsini, 1995; Porsolt et al, 1977b; Steru et al, 1985). As hypersecretion of corticosterone is associated with depression (Seckl et al, 1990), the change of plasma corticosterone level in GAT1 knockout mouse was also examined. Our results repeatedly confirm that GAT1 plays an important role in the pathogenesis of anxiety and depression, and suggest that GAT1 mutant mice represent a useful genetic animal model to understand the relationship between etiology of depression and anxiety and GABAergic system function.

\section{MATERIALS AND METHODS}

\section{Subjects}

GAT1 null mutant mice were generated in our laboratory (Cai et al, 2006). In the mutant mice, a $1.57 \mathrm{~kb}$ DNA fragment that contains the exon 2 and exon3 of the mouse GAT1 gene was replaced by a $1.37 \mathrm{~kb}$ neomycin-resistant gene cassette (neo) to eliminate the GAT1 gene activity. Chimeric male mice, generated by injecting the recombinant ES cells into C57BL/6J blastocysts, were bred to C57BL/ $6 \mathrm{~J}$ females to establish germline transmission of the mutant. GAT1 knockout heterozygotes $\left(\mathrm{GAT} 1^{+/-}\right.$) were crossed with wild-type $\mathrm{C} 57 \mathrm{BL} / 6 \mathrm{~J}$ mice for another two generations. These heterozygotes were then intercrossed to generate homozygous, heterozygotes, and wild-types mice for further experimentation. Mice were group housed (three to five per cage) under specific pathogen-free conditions with a $12-\mathrm{h}$ light/dark cycle (lights on at 0700) and provided ad libitum access to food and water until the age of 12-18 weeks. Age- and body weight-matched male mice were used for behavioral experiments. The experiments were conducted in an isolated behavioral testing room in the animal facility to avoid external distractions. Investigators observed animal behaviors through a videomonitor in another room without any information about the genotype or drug treatment of the mice. In order to facilitate adaptation to the experimental environment, mice were housed in the testing room for at least 1 week before the experiment. Mice were used only for one experiment. These animal experiments described were approved by the Institutional Animal Care and Use Committee.

\section{Drugs}

Amitriptyline, imipramine, fluoxetine, and buspirone were purchased from Sigma-Aldrich. Tiagabine was a kind gift from Shanghai Celstar Research Center for Biotechnology. Diazepam was purchased from Shanghai Jiufu Pharmaceutical Co., Ltd. These drugs were dissolved in saline before administration.

\section{Forced-Swimming Test}

Mice were placed in a Plexiglas cylinder $(10 \mathrm{~cm}$ internal diameter, $50 \mathrm{~cm}$ high) filled with $25-26^{\circ} \mathrm{C}$ water $(10 \mathrm{~cm}$ height). The behavior of the animals was evaluated manually and the immobility time was measured during 5 min experimentation. A mouse was judged to be immobile when it remained floating in the water, making only those movements necessary to keep its head above water (BilkeiGorzo et al, 2002; Porsolt et al, 1977a).

\section{Tail-Suspension Test}

Animals were injected intraperitoneally with a volume of $10 \mathrm{ml} / \mathrm{kg}$ of vehicle (saline) or antidepressant. Amitriptyline $(10 \mathrm{mg} / \mathrm{kg})$, imipramine $(5 \mathrm{mg} / \mathrm{kg})$, and fluoxetine $(20 \mathrm{mg} / \mathrm{kg})$ were used as the antidepressants. Forty minutes later, mouse was suspended individually by its tail from a metal rod. The rod was fixed $50 \mathrm{~cm}$ above the surface of a table covered with soft cloth in a sound-proof room. The tip of the mouse's tail was fixed on the rod using adhesive Scotch tape. The duration of the test was $5 \mathrm{~min}$. The immobility time of the tail-suspended mice was measured as previously described (Bilkei-Gorzo et al, 2002; Steru et al, 1985).

\section{Open-Field Test}

The open-field test was conducted in accordance with published reports (Holmes et al, 2003a,b; Mathis et al, 1994). The open field was a square arena $\left(50 \times 50 \times 50 \mathrm{~cm}^{3}\right)$ with clear Plexiglas walls and floor, brightly illuminated by overhead fluorescent lighting $\left(1.5 \mu \mathrm{mol} / \mathrm{m}^{2} / \mathrm{s}\right)$. Mice were placed in the center of the box and allowed to freely explore for a 10-min period. Mice were videotaped using a camera fixed above the floor and analyzed with a videotracking system (morris maze analyzer, V 1.1 by BGB). The defined 'margin' of the arena is $8 \mathrm{~cm}$ wide along the wall and the 'center' field is defined as the central $20 \times 20 \mathrm{~cm}^{2}$ area of the open field, approximately $16 \%$ of the total area.

\section{Light-Dark Exploration Test}

The light-dark exploration test was conducted as described previously (Crawley, 1981; Holmes et al, 2003a, b). The apparatus consisted of a polypropylene cage $\left(32 \times 16 \times 16 \mathrm{~cm}^{3}\right)$ separated into two compartments (dark and light) by a partition with a small opening $\left(8 \times 5 \mathrm{~cm}^{2}\right)$ at floor level, and equipped with infrared sensor that was used to monitor the number of transitions and the time spent in each chamber for each mouse. Ceiling lights were turned off during these experiments. The light half of the shuttle box was open-topped, transparent, and illuminated by a desk lamp $(100 \mathrm{~W})$. Mice were individually placed in the center of the light compartment, facing away from the partition, and allowed to freely explore the apparatus for $5 \mathrm{~min}$. The number of light-dark transitions between the two compartments and the total time spent in the dark compartment were recorded. 


\section{Emergence Test}

The emergence test was conducted as described previously (Holmes et al, 2003b; Smith et al, 1998; Takahashi et al, 1989). The apparatus consisted of an opaque black Plexiglas cube $\left(16 \times 16 \times 19 \mathrm{~cm}^{3}\right)$ with an exit $\left(6 \times 4 \mathrm{~cm}^{2}\right)$ on one side at floor level. This 'shelter' was placed within an open field $\left(50 \times 50 \times 50 \mathrm{~cm}^{3}\right)$, brightly illuminated by overhead fluorescent lighting, with the exit facing out into the open field (parallel with one wall of the open field). Mice were first placed inside the shelter for a 5-min habituation period with the exit closed. After that, the exit was opened to allow the mouse leave the shelter and explore the open field for $5 \mathrm{~min}$. For each mouse, the latency to emerge from the shelter, time spent out of the shelter and shelter open-field transitions were recorded.

\section{EPM}

The EPM was conducted as described previously (File, 2001; Holmes et al, 2003a; Lister, 1987). The apparatus comprised of two open arms $\left(25 \times 8 \mathrm{~cm}^{2}\right)$ and two closed arms $\left(25 \times 8 \times 12 \mathrm{~cm}^{3}\right)$ that extended from a common central platform $\left(8 \times 8 \mathrm{~cm}^{2}\right)$. A small raised lip $(0.5 \mathrm{~cm})$ around the edges of the open arms prevented animals from slipping off. The apparatus was constructed from polypropylene and Plexiglas (white floor, clear walls) and elevated to a height of $50 \mathrm{~cm}$ above the floor. Mice were allowed to habituate to the testing room for 2 days before the test, and pretreated with gentle handling two times per day to eliminate their nervousness. For drug treatment experiments, mice were injected intraperitoneally with a volume of $10 \mathrm{ml} / \mathrm{kg}$ of vehicle (saline) or drugs, buspirone $(1 \mathrm{mg} / \mathrm{kg})$, diazepam ( $1 \mathrm{mg} / \mathrm{kg})$, and tiagabine $(8 \mathrm{mg} / \mathrm{kg}), 40 \mathrm{~min}$ before the EPM test was performed. Mice were individually placed on the center square, facing an open arm, and allowed to freely explore the apparatus under even overhead fluorescent lighting $\left(1.5 \mu \mathrm{mol} / \mathrm{m}^{2} / \mathrm{s}\right)$ for $10 \mathrm{~min}$. Mice were videotaped using a camera fixed above the maze and analyzed with a video-tracking system (morris maze analyzer. V 1.1 by BGB). Open and closed arm entries (all four paws in an arm) were scored by an experienced observer.

\section{Stress Hormone Measurements}

Blood was collected from mice by decapitated bleeding immediately after $10 \mathrm{~min}$ of physical restraint (15 min restraint in a $50 \mathrm{ml}$ conical tube) or from rest in the home cage (0900-1000), spun through a serum separator tube at $1000 \mathrm{~g}$ for $15 \mathrm{~min}$, and stored at $-20^{\circ} \mathrm{C}$ until use. Corticosterone measurements were performed on serum using a Corticosterone immunoassay (R\&D Systems) according to the manufacturer's instructions.

\section{Statistical Analysis}

Mean values and SE were calculated for each group, and groups were compared using one-way ANOVA followed by $t$-test. $p<0.05$ denotes a statistically significant difference. Wild-type, heterozygous, and homozygous GAT1-deficient mice are designated as $+/+,+/-$, and $-/-$; and the number of mice used are designated as $n^{+/+}, n^{+/-}$, and $n^{-l-}$, respectively.

\section{RESULTS}

\section{Reduced Depression-Like Behaviors in GAT1-Deficient Mice}

The forced-swimming test (Porsolt et al, 1977a, b) and the tail-suspension test (Bilkei-Gorzo et al, 2002; Steru et al, 1985) were employed in this study to evaluate the tendency towards depression-like behavior in the genotypically different mice groups. Both experimental schemes are based on the observation that rodents, when forced into an aversive situation from which they cannot escape, will cease attempts to escape and become immobile. Antidepressants reduce the immobility time in these tests (Porsolt, 2000; Steru et al, 1987) indicating that these methods can be used to test for depression-related behavior in mice. In the forced-swimming test, as shown in Figure 1a, immobility time for GAT1 $1^{-l-}$ mice was significantly lower than that of $\mathrm{GAT}^{+/-}$and GAT1 ${ }^{+/+}$animals $(\mathrm{F}(2,33)=63, p<0.001)$ (Figure 1a). This phenomenon was also observed in the tailsuspension test, which showed significantly reduced immobility time in $\mathrm{GAT} 1^{-/-}$mice compared to $\mathrm{GAT} 1^{+/+}$ mice $(\mathrm{F}(2,16)=16, p<0.001)$ (Figure $1 \mathrm{~b})$. Treatment of mice with the selective serotonin reuptake inhibitor, fluoxetine and a tricyclic uptake inhibitor, amitriptyline significantly reduced immobility time in GAT1 ${ }^{+/+}$and $\mathrm{GAT}^{+/-}$mice, but not in $\mathrm{GAT}^{-I-}$ mice. However, a similar response to another tricyclic uptake inhibitor, imipramine was observed in all three groups (Figure 1b). These findings indicate that prolonged changes in GABAergic homeostasis affect the depression-related behavioral tendency of mice with possible involvement of the serotonergic system.

\section{Reduced Anxiety-Like Behaviors in GAT1 Knockout Mice}

Next, we examined the differences in behavior of wild-type, heterozygous, and homozygous GAT1-deficient mice in the open field, which is widely used in laboratories to quantify anxiety-like and locomotor behaviors in mice (Crawley, 1999). Mice prefer to move around the periphery of an apparatus when they are placed in an open field of a novel environment. It is thought that the time spent in the central area of the open field is inversely correlated to their level of anxiety-related proneness. As shown in Table $1, \mathrm{GAT} 1^{-1-}$ mice spent longer time in central area and made more entries $(F(2,51)=3.79, p=0.029)$ into the central area than other two genotype mice. Meanwhile, $\mathrm{GAT}^{-1-}$ mice displayed hyperactivity and enhanced locomotion. This phenotype manifested as a significant increase in move time $(\mathrm{F}(2,51)=26.3, p<0.001)$, velocity $(\mathrm{F}(2,51)=9.23$, $p<0.001)$, and distance traveled $(\mathrm{F}(2,51)=8.46, p<0.001)$ in $\mathrm{GAT}^{-1-}$ mice. There was also a significantly higher number of rearings for $\mathrm{GAT}^{-I-}$ mice $(\mathrm{F}(2,51)=7.63$, $p=0.002$ ).

As the results of the open-field experiments suggested that GAT1 knockout leads to a reduction in anxiety-like behaviors, we decided to confirm these observations using additional tests.

The light-dark exploration paradigm, which is based on the innate aversion of rodents to brightly illuminated areas 

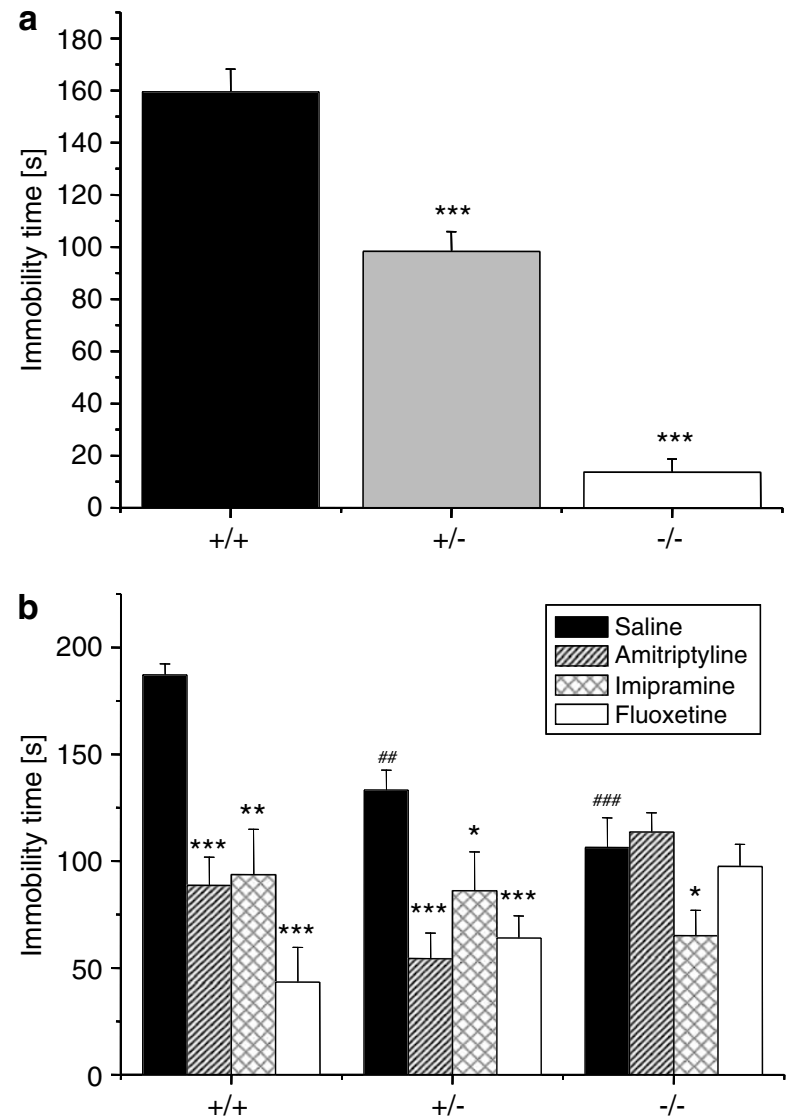

Figure I $\mathrm{GATI}^{-1-}$ mice showed reduced depression-like behaviors in forced-swimming test and tail-suspension test. (a) Forced-swimming test ( $n=12$ per group). The behavior of the genotypically different mice was measured during a $5 \mathrm{~min}$ forced swim test. The immobility time for wildtype, heterozygous, and homozygous mice were $159.4 \pm 8.7 \mathrm{~s} ; 98.3 \pm 7.6 \mathrm{~s}$; $13.6 \pm 5.1$ s, respectively. ${ }^{*} * * * 2<0.001$ (one-way ANOVA followed by $t-$ test). (b) Tail-suspension test. Mice were injected with saline $\left(n^{+/+}=6\right.$, $\left.n^{+l-}=7, n^{-1-}=6\right)$, or $10 \mathrm{mg} / \mathrm{kg}$ amitriptyline $\left(n^{+1+}=7, n^{+1-}=6, n^{-1-}=8\right)$, or $5 \mathrm{mg} / \mathrm{kg}$ imipramine $\left(n^{+9+}=7, \mathrm{n}^{+1-}=6, \mathrm{n}^{-1-}=8\right)$, or $20 \mathrm{mg} / \mathrm{kg}$ fluoxetine $\left(n^{+1+}=5, n^{+/-}=5, n^{-1-}=5\right)$ as described in Materials and methods. The immobility time was measured during a 5 min tail-suspension test. $\# \# p<0.01, \# \# \#<0.001$, vs wild-type mice treated with vehicle. ${ }^{*} p<0.05, * * p<0.01$, **** $p<0.00$ I, vs the same genotype treated with vehicle (one-way ANOVA). Values are presented as the mean \pm SEM.

and on the spontaneous exploratory behavior of the animals, is used primarily to detect anxiogenic behavior (Hascoet et al, 2001). GAT1 ${ }^{-1-}$ mice spent significantly less time in the dark chamber than wild-type mice $(\mathrm{F}(2,43)=8.38, p<0.001)$ (Figure $2 \mathrm{~b}$ ), and made more transitions $(\mathrm{F}(2,43)=6.97, p=0.002)$ (Figure $2 \mathrm{a})$, suggesting a reduction in anxiety-like behavior.

The results of emergence test are presented in Figure 2c-e. There was a significant genotypic effect on shelter open-field transitions and the percentage time spent out of the shelter, but not for the latency to initially exit the shelter $(\mathrm{F}(2,18)=0.45, p=0.65)$. One-way ANOVA analysis showed that $\mathrm{GAT}^{-1-}$ mice made more shelter open-field transitions $(\mathrm{F}(2,18)=6.52, p=0.007)$ and spent more time out of the shelter $(\mathrm{F}(2,18)=10.9, p<0.001)$ than wild-type mice.

High levels of anxiety are thought to be associated with a reduced activity of mice in the open compartments in the
Table I Performance of GATI ${ }^{-1-}$ Mice in Open Field

\begin{tabular}{|c|c|c|c|}
\hline \multirow[b]{2}{*}{ Parameter } & \multicolumn{3}{|c|}{ Genotype } \\
\hline & $+/+(n=13)$ & $+l-(n=20)$ & $-I-(n=2 I)$ \\
\hline Move time (s) & $287 \pm 17.4$ & $361 \pm 12.1$ 米米米 & $429 \pm 13.0$ ****** \\
\hline Rest time (s) & $314 \pm 17.4$ & $239 \pm 12.1$ 粎米 & $17| \pm| 3.0$ ****** \\
\hline Distance $(\mathrm{cm})$ & $2237 \pm 214.0$ & $2459+|4| .4 *$ & $3477 \pm 298.6 * * * *$ \\
\hline Velocity $(\mathrm{cm} / \mathrm{s})$ & $3.7 \pm 0.3$ & $4.2 \pm 0.2 *$ & $6.0 \pm 0.5 * * * *$ \\
\hline Margin distance $(\mathrm{cm})$ & $1844 \pm 204.5$ & $2047 \pm 114.6 * *$ & $2896 \pm 274.6$ **** \\
\hline Margin time $(s)$ & $537 \pm 9.50$ & $511 \pm 17.5$ & $503 \pm 22.2$ \\
\hline Center distance $(\mathrm{cm})$ & $114 \pm 15.5$ & $136 \pm 29.9$ & $181 \pm 43.3$ \\
\hline Center time (s) & $16.5 \pm 2.90$ & $37.4 \pm 10.0$ & $26.9 \pm 3.47$ \\
\hline Center entries & $6.5 \pm 1.1$ & $6.7 \pm 1.4$ & $\mid 1 \pm 2.1 *$ \\
\hline Rears & $15.6 \pm 1.90$ & $16.0 \pm 3.20$ & $44.2 \pm 9.10 * *$ \\
\hline
\end{tabular}

Velocity $(\mathrm{cm} / \mathrm{s})=$ distance $(\mathrm{cm}) /$ total time $(\mathrm{s})$.

**** $p<0.00$ I; *** $<0.0$ I; $*$ $p<0.05$, mean \pm SEM, vs wild-type mice.

EPM test (Shepherd et al, 1994). The results showed that $\mathrm{GAT}^{-1-}$ mice spent more time in the open arm $(\mathrm{F}(2,35)=42, p<0.001)$ (Figure 3a), more entries into the open $\operatorname{arm}(\mathrm{F}(2,35)=17, p<0.001)$ (Figure $3 \mathrm{~b}$ ), and more time on the center platform $(\mathrm{F}(2,34)=3.4, p=0.04)$ (Figure 3d), but not in closed arm entries $(\mathrm{F}(2,35)=0.54$, $p=0.58)$ (Figure $3 c$ ). Treatment of wild-type animals with anxiolytic agents (buspirone, diazepam), or a GAT1 inhibitor (tiagabine) significantly increased their activity in the open arms and reduced their activity in the close arms (Figure 3). However, the same treatment on GAT1 $1^{-1-}$ mice had less effect on its behavior in elevated plus maze test (Figure 3).

\section{Stress Hormone Measurements}

Reduced anxiety-like behavior in mice can be associated with low levels of serum corticosterone (Smith et al, 1998). To determine if the reduced anxiety correlates with low levels of hormones in GAT1 $1^{-I-}$ mice, we measured serum corticosterone levels from naïve mice and from mice after $10 \mathrm{~min}$ of physical restraint-induced stress. Wild-type and $\mathrm{GAT}^{-l-}$ mice that had undergone restraint-induced stress exhibited a significantly higher corticosterone levels than naïve mice. There were no differences between wildtype and $\mathrm{GAT}^{-l-}$ mice in this respect (Figure 4 ). However, baseline corticosterone levels were significantly lower in $\mathrm{GAT} 1^{-1-}$ mice than in wild-type mice $(\mathrm{F}(2,12)=$ $8.1, p=0.007)$. These data suggest that the activity of the hypothalamic-pituitary-adrenal (HPA) is reduced in the GAT1 knockout mice under general conditions in the home cage.

\section{DISCUSSION}

GABA is the most important inhibitory neurotransmitter in the central nervous system (CNS), and GABAergic systems play an important role in the pathophysiology of depression and anxiety. It has been observed by magnetic resonance 

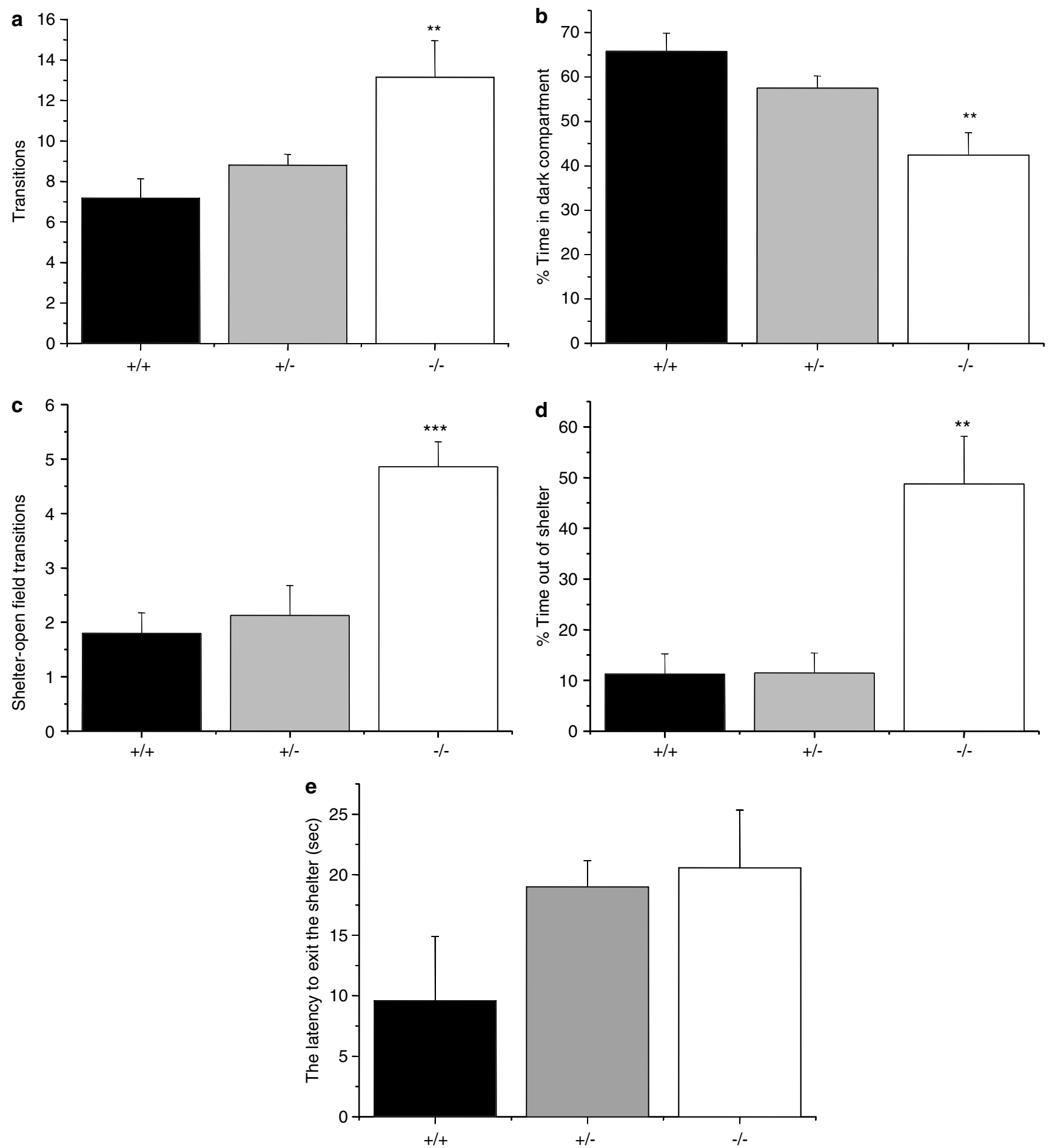

Figure $2 \mathrm{GATI}^{-1-}$ mice showed reduced anxiety-like behaviors in the light-dark exploration and emergence tests. (a) In the light-dark exploration test $\left(n^{+1+}=17, n^{+1-}=15, n^{-l-}=14\right)$. GATI ${ }^{-1-}$ mice made more light-dark transitions. (b) GATI ${ }^{-1-}$ mice spent less time in the dark compartment than $\mathrm{GATI}^{+1+}$ mice. (c) In the emergence test $\left(n^{+1+}=6, \mathrm{n}^{+1-}=8, \mathrm{n}^{-1-}=7\right.$ ). GATI ${ }^{-1-}$ mice made more shelter open-field transitions. (d) GATI ${ }^{-1-}$ mice spent more time out of the shelter than GATI ${ }^{+/+}$mice. (e) The first time to exit the shelter of GATI ${ }^{-1-}$ mice is longer than GATI ${ }^{+/+}$mice, but the difference is not significant. ${ }^{*} p<<0.01$; $* * * * 0<0.001$ vs GATI ${ }^{+/+}$mice.

spectroscopy that unipolar depression is associated with reductions in cortical GABA levels in patients (Krystal et al, 2002). In addition, tiagabine, a GAT1 inhibitor, has been used for the treatment of anxiety disorders (Crane, 2003; Lydiard, 2003; Schaller et al, 2004; Schmitt and Hiemke,
1999). These observations provide a rationale to examine mood-related behavior changes in $\mathrm{GAT}^{-1-}$ mice.

The forced-swimming and tail-suspension tests are the most widely used animal models for antidepressant drug screening. Immobility, a posture to reflect a state of 

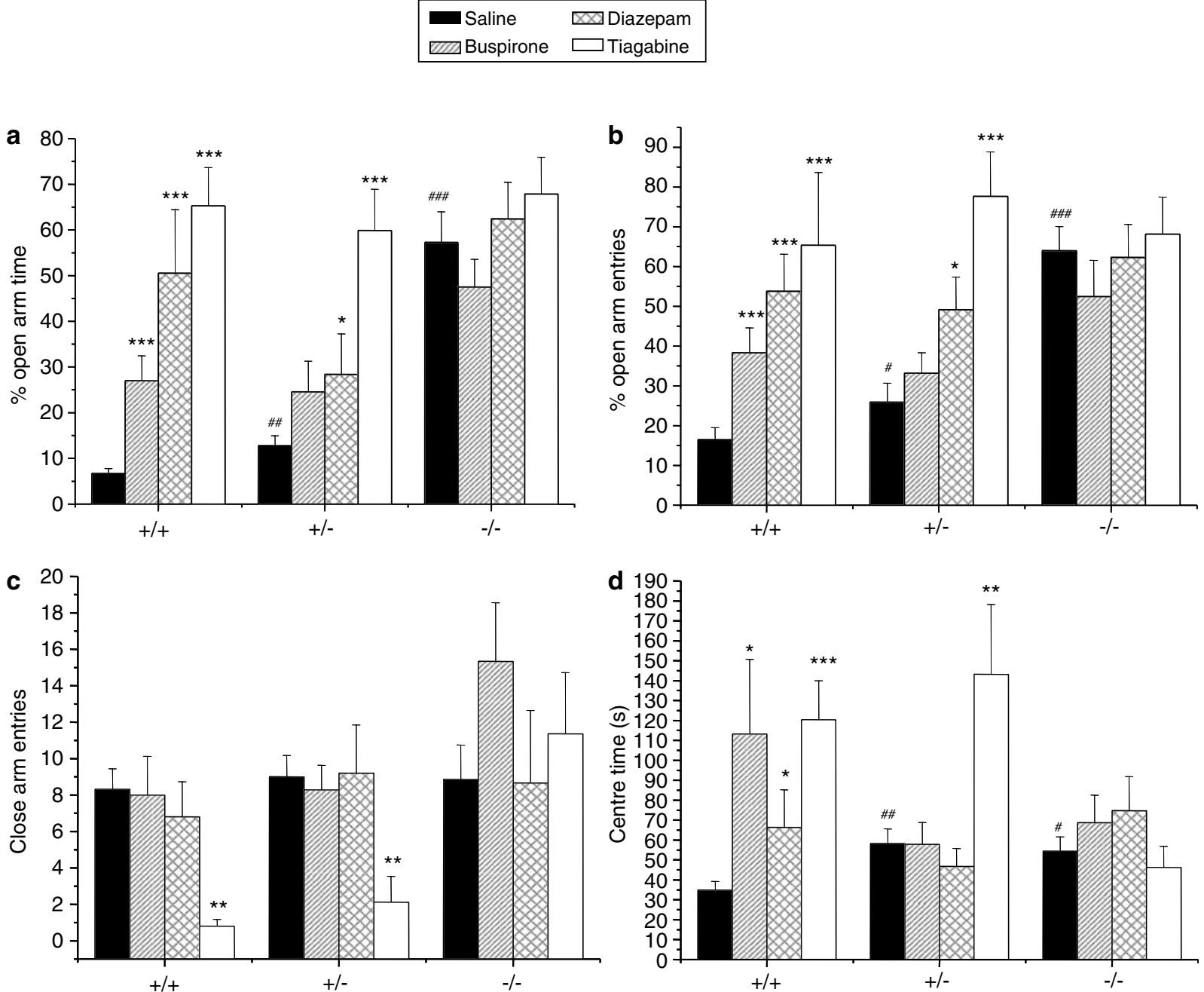

Figure $3 \mathrm{GATI}^{-1-}$ mice showed reduced anxiety-like behaviors in EPM. The anxiolytic agents, buspirone $(\mathrm{I} \mathrm{mg/kg})\left(n^{+1+}=8, n^{+1-}=7, n^{-1-}=6\right)$ and diazepam $(\mathrm{l} \mathrm{mg} / \mathrm{kg})\left(\mathrm{n}^{+/+}=5, \mathrm{n}^{+/-}=5, \mathrm{n}^{-1-}=6\right)$, and the GATI inhibitor tiagabine $(8 \mathrm{mg} / \mathrm{kg})\left(n^{+1+}=6, \mathrm{n}^{+/-}=8, \mathrm{n}^{-1-}=9\right)$, produced anxiolytic-like effects in $\mathrm{GATI}^{+}+$mice but not GATI ${ }^{-1-}$ mice. GATI ${ }^{-1-}$ mice (a) spent more open arm time, (b) made more open arm entries and (d) spent more time on the center platform than GATI ${ }^{+1+}$ mice. (a) Increased percent open arm time, (b) percent open arm entries and (d) time spent on the center platform in $\mathrm{GATI}^{+/+}$and GATI ${ }^{+-}$mice was seen at all doses tested, with no effect in GATI ${ }^{-1-}$ mice. There was no difference in (c) closed arm entries between $\mathrm{GATI}^{+1+}$ and $\mathrm{GATI}^{-1-}$ control mice. There were 12 mice per group treated with the vehicle. Tiagabine decreased closed arm entries in GATI ${ }^{+1+}$ and $\mathrm{GATI}^{+1-}$ mice but not in GATI ${ }^{-1-}$ mice. ${ }^{\#} p<0.05,{ }^{\# \#} p<0.0$ I, ${ }^{\# \# \#} p<0.00$ I, vs wild-type mice treated vehicle. ${ }^{*} p<0.05$, , $*$ * $p<0.0$ I, **** $p<0.00$ I, vs the same genotype treated with vehicle (one-way ANOVA).

'behavioral despair' in which animals no longer escape, is thought to be related to depression, and drugs with antidepressant activity reduce the time that the animals remain immobile (Bilkei-Gorzo et al, 2002; Borsini et al, 1988; Porsolt et al, 1977a). In our present study, we found a significantly reduced immobility time for $\mathrm{GAT}^{-1-}$ mice in both tests. These behavioral effects are similar to those that we and other investigators have observed for wild-type animals treated with antidepressant drugs, such as amitriptyline, imipramine, and fluoxetine (Figure 1b) (BilkeiGorzo et al, 2002; Borsini et al, 1988; Porsolt et al, 1977a).

Fluoxetine, a selective serotonin reuptake inhibitor, has high affinity for the 5-HTT. The time spent immobile in the tail-suspension test of wild-type mice was significantly reduced by acute administration of fluoxetine, which occurs via increased availability of 5-HT following 5-HTT blockade. In marked contrast, GAT1 ${ }^{-1-}$ mice were totally insensitive to the anti-immobility effects of fluoxetine in the same test. Amitriptyline and imipramine, being tricyclic antidepressants, have high affinities for the 5-HTT and norepinephrine transporter (NET), and demonstrate significant effects on wild-type mice in tail-suspension tests. Amitriptyline, like fluoxetine, also showed no behavioral effects on $\mathrm{GAT}^{-I-}$ mice, however, it is interesting that imipramine had similar effects on $\mathrm{GAT}^{-1-}$ mice as on wild-type mice. These findings indicate serotonergic and adrenergic systems may have been modified in GAT1 mutant mice secondary to the modification in the GABAergic system. This hypothesis is weakly supported by the report that mice lacking the serotonin transporter exhibit similar pharmacological effects to fluoxetine (Holmes et al, 2002). Amitriptyline and imipramine are antidepressants with more mixed pharmacological profiles. They have high affinity for both 5-HTT and NET, and 


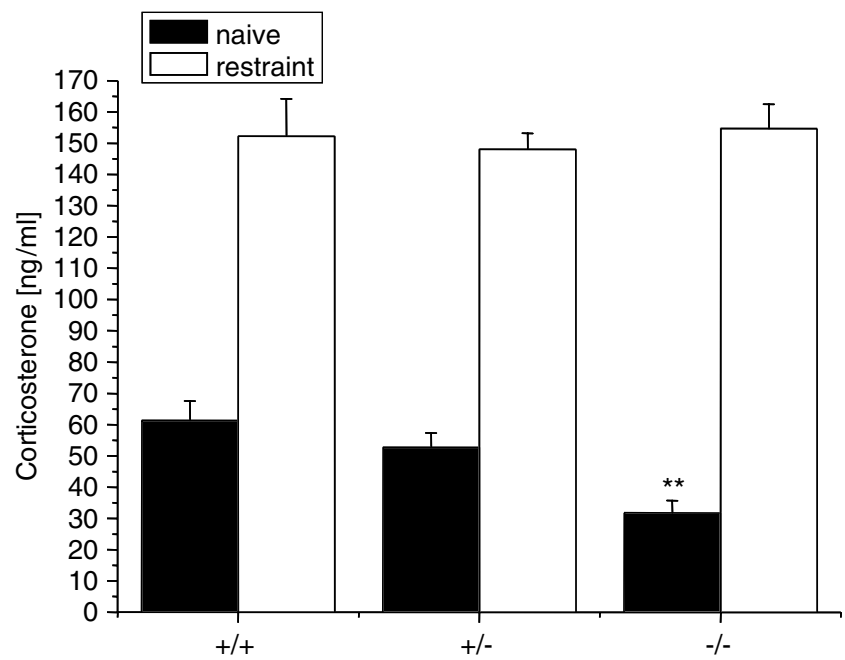

Figure 4 Normal and stress-induced corticosterone levels in GATI ${ }^{-1-}$ mice serum. GATI ${ }^{+1+}$ and $\mathrm{GATI}^{-1-}$ mice were removed from home cage (naive) or exposed to $10 \mathrm{~min}$ of physical restraint-induced stress. Blood was collected from mice by decapitated bleeding immediately $\left(n^{+/+}=5, n^{+/-}=5, n^{-1-}=5\right)$. Columns and bars represent mean \pm SEM, respectively. ${ }^{*} * p<0.01$ vs GATI ${ }^{+1+}$ mice.

similar effects on wild-type mice. However, they have different pharmacological effects on $\mathrm{GAT} 1^{-1-}$ mice in the tail-suspension test. These data indicate that the action of amitriptyline and imipramine in the mouse CNS could be different. It has been reported that imipramine has a higher affinity for 5-HTT and NET than amitriptyline (Frazer, 1997) and a relatively higher affinity for $\mathrm{H}_{1}$ histamine, $\alpha_{1}$-adrenergic, and cholinergic receptors than fluoxetine (Frazer, 1997). Our results support the idea that the GAT1 is involved in the pathophysiology of depression. Such a role was also suggested by a recent clinical study that demonstrated the efficacy of the GAT1 antagonist tiagabine in patients with a major depressive disorder (Crane, 2003).

Anxiety-like behavior and exploratory locomotion in GAT1 null mutant mice were studied using four separate behavioral paradigms. GAT1 ${ }^{-1-}$ mice were more active in the open field, spent more time in the central area and showed more rearing postures and center entries than GAT $1^{+/+}$mice. The phenomenon is consistent with a reduced anxiety-like behavior (ie, increase center time) and increased locomotor exploration (ie, increase horizontal and vertical activities). It has been demonstrated that in exploration-based tests for anxiety-like behaviors, such as the light-dark exploration or emergence tests, animals with anxiety would rather spend more time in the dark compartment (Blanchard et al, 1990; File, 2001; Holmes et al, 2003b). In light-dark exploration tests, the GAT1 ${ }^{-1-}$ mice showed more transitions between light and dark compartments and spent more time in the light compartment than GAT1 ${ }^{+/+}$mice. These results indicate that the GAT $1^{-I-}$ mice were prone to exhibit reduced anxiety. Alternatively, the absence of an anxiety-like preference for the dark compartment in $\mathrm{GAT}^{-1-}$ mice might indicate that these animals demonstrate behavioral inhibition because of placement in the light compartment at the start of the test session, so that skewed scores might show a false light compartment preference. In order to avoid drawing false conclusions, the emergence test was introduced as interpretation is less likely to be confounded by behavioral inhibition caused by precipitous exposure to an aversive light stimulus. In this test, the animals were initially placed within a protected, darkened shelter before the light-dark conflict phase. Here also, GAT1 ${ }^{-1-}$ mice showed increased exploration and preferred a brightly illuminated arena, as compared to the GAT1 ${ }^{+/+}$mice. These data suggest that the light compartment preference of $\mathrm{GAT}^{-/-}$mice could be a reduced anxiety-like behavior, rather than behavioral inhibition. The result of the EPM test confirmed that GAT $1^{-1-}$ mice demonstrate reduced anxiety-like behaviors. In the EPM, GAT1 ${ }^{+/+}$mice showed a greater avoidance of the aversive open arms than GAT1 $1^{-1-}$ mice, consistent with reduced anxiety-like behavior in $\mathrm{GAT} 1^{-/-}$mice on this test. In summary, our results from the four different test paradigms indicate that GAT1-deficient mice were generally less anxious than control mice.

To further investigate the role of GAT1 in anxiety behaviors, three anxiolytic drugs: buspirone, diazepam, tiagabine that have different molecular targets were were chosen to study their effects on GAT1 mutant mice using the behavioral model of the EPM. Diazepam and tiagabine act on the GABAergic system. Diazepam is an agonist at $\mathrm{BDZ}$ sites to enhance $\mathrm{Cl}^{-}$current of $\mathrm{GABA}_{\mathrm{A}}$, and is a benzodiazepine with CNS depressant properties (Banfi et al, 1982; Atack, 2005). Tiagabine hydrochloride, a selective GABA-reuptake inhibitor, increases GABA tone via GAT1 blockade (Nielsen et al, 1991; Rekling et al, 1990). Buspirone, a serotonin1A receptor partial agonist, also displays an antagonist effect on $\mathrm{D}(2)$-dopamine and the $\alpha 2$ adrenergic receptors (Gobert et al, 1999). Treatment of wild-type animals with these drugs significantly increased the activity in the open arms of EPM test. However, mice lacking the $\mathrm{GAT}^{-I-}$ were insensitive to the behavioral effects of these drugs.

As expected, $\mathrm{GAT}^{-l-}$ mice were completely insensitive to tiagabine, the GAT1 inhibitor. The failed effect of diazepam (the BDZ agonist) on the mutant mice indicates that $\mathrm{GABA}_{\mathrm{A}}$ receptor function was modulated by dysfunction of GABA reuptake and the consequential nervous system adaptation. The pharmacological effects of buspirone on $\mathrm{GAT}^{-l-}$ mice together with the results of fluoxetine and amitriptyline further suggest alterations to the serotonergic system of the mutant mice. These might be explained by complex interactions between GABAergic and serotonergic systems (Katsurabayashi et al, 2003; Tao and Auerbach, 2000). Serotonin release could be regulated by GABA in brain. Muscimol, a $\mathrm{GABA}_{\mathrm{A}}$ receptor agonist, reduced while bicuculline, a $\mathrm{GABA}_{\mathrm{A}}$ receptor blocker, produced an approximately three-fold increase in the dorsal raphé nucleus serotonin (Tao and Auerbach, 2000). In $\mathrm{GAT}^{-l-}$ mice, the deficiency of GABA reuptake in brain may lead overflow of released GABA to from the synaptic cleft. We hypothesize that the overflow GABA in the GAT $1^{-l-}$ mouse brain enhanced the tonic inhibition of GABAergic interneurons, with subsequent reduction in released GABA by these interneurons that act on serotonergic systems. Moreover, the excitability of GABAergic interneurons could also be modified by 5-HT. 8-Hydroxy2-dipropylaminotetralin, a 5-HT(1A) agonist, presynaptically decreased electrically evoked GABA release whereas 
m-chlorophenylbiguanide, a 5-HT(3) agonist, presynaptically facilitated GABA release (Katsurabayashi et al, 2003). These actions are likely related to its anxiolytic effects. As these effects were absent in GAT1 $1^{-1-}$ mice, we supposed that the dopaminergic and adrenergic systems may also have been modified secondary to GABAergic system changes. Another possibility to explain the $\mathrm{GAT} 1^{-1-}$ mice insensitive to the behavioral effects of anxiolytic drugs is the ceiling effect. As they were already showing less anxiety in normal status.

Jensen et al (2003) recently reported a GAT1-deficient mouse strain, intron-14-neo-intact-mGAT1, in which a neomycin resistance cassette (neo) was inserted in intron 14. A green fluorescent protein (GFP) moiety was also fused to the C-terminus of the mGAT1 coding region in exon 14 (Jensen et al, 2003). This mouse strain was originally constructed as a genetic intermediate in the eventual construction of a neo-deleted mGAT1-GFP knockin strain (Chiu et al, 2002). Although the exact mechanism for gene knockout by such a manner has not been illustrated, inhibition of GAT1 expression in mutant mouse brain was proven. An anxiety-prone behavior, which differed from our results with the open field and EPM tests, was observed in these mice (Jensen et al, 2003). These differences may be attributed to the different genetic background between the two mutant mice strains (C57BL/6J in the studies of Chiu et al (2005), whereas, mixed C57BL/6J and 129SvJ genetic background mice were used in our studies). However, the different strategy for making GAT1 knockout mice could contribute to the results of different phenotype. Unlike Chiu's model, in our mutant mice the GAT1 gene was completely deleted in every cell type from the beginning of development. We show here that GAT1 gene deletion results in clearly reduced anxiety-like behaviors in mice by various well-established methods.

Many patients with severe major depressive episodes have dysregulated circadian cortisol control with significantly higher blood levels than healthy control subjects (Strickland et al, 2002; Urani et al, 2005). Elevated cortisol levels in depressed patients usually return to normal following successful antidepressant treatment (Wolkowitz et al, 1993, 1999). Previous studies have demonstrated that classical benzodiazepines decrease HPA cortex axis activity (Mikkelsen et al, 2005) and a low serum corticosterone levels could be associated with reduced anxiety (Ferguson et al, 2004; Smith et al, 1998). We investigated the function of the HPA axis in $\mathrm{GAT} 1^{-1-}$ mice by measuring corticosterone levels following physical restraint-induced stress and during normal activity. Corticosterone levels were lower in the $\mathrm{GAT}^{-l-}$ mice than that in wild-type mice during normal activity. However, there were no differences between the different genotypes under stress. This suggests that the function of the HPA axis in GAT $1^{-1-}$ mice was modified under normal conditions, but its sensitivity to stress might not be changed.

In conclusion, our results support the hypothesis that the regulation of GAT1 function affects anxiety and depressionlike behaviors. Based on our observations in $\mathrm{GAT}^{-1-}$ and GAT $1^{+/-}$mice with absent and low GAT-1 expression, respectively, our data provide insights to the contribution of GAT1 expression in the manifestation of these mental disorders. Therefore, drugs that can regulate the function or expression of GAT1 with subsequent modulation of the GABAergic system may have therapeutic value in the treatment of these mental illnesses. GAT $1^{-1-}$ mice can provide a useful tool to further delineate the pharmacological actions of antidepressants and anxiolytics, and the pharmacogenetics of depression and anxiety.

\section{ACKNOWLEDGEMENTS}

This work was supported in part by Grants from the National Natural Science Foundation of China (30370447), Chinese Academy of Sciences, Science, and Technology Commission of Shanghai Municipality (03DZ14018, 03DJ14088) and E-Institutes of Shanghai Municipal Education Commission (Project Number: E03003). We thank Dr Eroboghene E Ubogu and Dr Gurunathan Murugesan for their helpful discussions and critical review of the manuscript. We thank Mrs Xixia Zhou for the care of the animals used in this study, as well as Mrs Jing Gu and Mrs Hui Gao from the National Key Laboratory of Medical Neurobiology, Fu Dan University for their technical help.

\section{REFERENCES}

Atack JR (2005). The benzodiazepine binding site of GABA(A) receptors as a target for the development of novel anxiolytics. Expert Opin Invest Drugs 14: 601-618.

Banfi S, Cornelli U, Fonio W, Dorigotti L (1982). A screening method for substances potentially active on learning and memory. J Pharmacol Methods 8: 255-263.

Bilkei-Gorzo A, Racz I, Michel K, Zimmer A (2002). Diminished anxiety- and depression-related behaviors in mice with selective deletion of the Tacl gene. J Neurosci 22: 10046-10052.

Blanchard DC, Blanchard RJ, Tom P, Rodgers RJ (1990). Diazepam changes risk assessment in an anxiety/defense test battery. Psychopharmacology (Berl) 101: 511-518.

Borden LA (1996). GABA transporter heterogeneity: pharmacology and cellular localization. Neurochem Int 29: 335-356.

Borsini F (1995). Role of the serotonergic system in the forced swimming test. Neurosci Biobehav Rev 19: 377-395.

Borsini F, Mancinelli A, D’Aranno V, Evangelista S, Meli A (1988). On the role of endogenous GABA in the forced swimming test in rats. Pharmacol Biochem Behav 29: 275-279.

Cai YQ, Cai GQ, Liu GX, Cai Q, Shi JH, Shi J et al (2006). Mice with genetically altered GABA transporter subtype I (GAT1) expression show altered behavioral responses to ethanol. J Neurosci Res 84: 255-267.

Chiu CS, Brickley S, Jensen K, Southwell A, McKinney S, CullCandy $S$ et al (2005). GABA transporter deficiency causes tremor, ataxia, nervousness, and increased GABA-induced tonic conductance in cerebellum. J Neurosci 25: 3234-3245.

Chiu CS, Jensen K, Sokolova I, Wang D, Li M, Deshpande P et al (2002). Number, density, and surface/cytoplasmic distribution of GABA transporters at presynaptic structures of knock-in mice carrying GABA transporter subtype 1-green fluorescent protein fusions. J Neurosci 22: 10251-10266.

Crane D (2003). Tiagabine for the treatment of anxiety. Depress Anxiety 18: 51-52.

Crawley JN (1981). Neuropharmacologic specificity of a simple animal model for the behavioral actions of benzodiazepines. Pharmacol Biochem Behav 15: 695-699.

Crawley JN (1999). Behavioral phenotyping of transgenic and knockout mice: experimental design and evaluation of general health, sensory functions, motor abilities, and specific behavioral tests. Brain Res 835: 18-26. 
Ferguson GD, Herschman HR, Storm DR (2004). Reduced anxiety and depression-like behavior in synaptotagmin IV $(-/-)$ mice. Neuropharmacology 47: 604-611.

File SE (2001). Factors controlling measures of anxiety and responses to novelty in the mouse. Behav Brain Res 125: 151-157.

Frazer A (1997). Antidepressants. J Clin Psychiatry 58(Suppl 6): 9-25.

Gobert A, Rivet JM, Cistarelli L, Melon C, Millan MJ (1999). Buspirone modulates basal and fluoxetine-stimulated dialysate levels of dopamine, noradrenaline and serotonin in the frontal cortex of freely moving rats: activation of serotonin $1 \mathrm{~A}$ receptors and blockade of alpha2-adrenergic receptors underlie its actions. Neuroscience 93: 1251-1262.

Guastella J, Nelson N, Nelson H, Czyzyk L, Keynan S, Miedel MC et al (1990). Cloning and expression of a rat brain GABA transporter. Science 249: 1303-1306.

Hascoet M, Bourin M, Dhonnchadha BA (2001). The mouse lightdark paradigm: a review. Prog Neuropsychopharmacol Biol Psychiatry 25: 141-166.

Holmes A, Kinney JW, Wrenn CC, Li Q, Yang RJ, Ma L et al (2003a). Galanin GAL-R1 receptor null mutant mice display increased anxiety-like behavior specific to the elevated plusmaze. Neuropsychopharmacology 28: 1031-1044.

Holmes A, Yang RJ, Lesch KP, Crawley JN, Murphy DL (2003b). Mice lacking the serotonin transporter exhibit 5-HT(1A) receptor-mediated abnormalities in tests for anxiety-like behavior. Neuropsychopharmacology 28: 2077-2088.

Holmes A, Yang RJ, Murphy DL, Crawley JN (2002). Evaluation of antidepressant-related behavioral responses in mice lacking the serotonin transporter. Neuropsychopharmacology 27: 914-923.

Jensen K, Chiu CS, Sokolova I, Lester HA, Mody I (2003). GABA transporter-1 (GAT1)-deficient mice: differential tonic activation of GABAA versus GABAB receptors in the hippocampus. $J$ Neurophysiol 90: 2690-2701.

Johnston GA (1996). GABAA receptor pharmacology. Pharmacol Ther 69: 173-198.

Kalueff A, Nutt DJ (1996). Role of GABA in memory and anxiety. Depress Anxiety 4: 100-110.

Katsurabayashi S, Kubota H, Tokutomi N, Akaike N (2003). A distinct distribution of functional presynaptic 5-HT receptor subtypes on GABAergic nerve terminals projecting to single hippocampal CA1 pyramidal neurons. Neuropharmacology 44: 1022-1030.

Krystal JH, Sanacora G, Blumberg H, Anand A, Charney DS, Marek $\mathrm{G}$ et al (2002). Glutamate and GABA systems as targets for novel antidepressant and mood-stabilizing treatments. Mol Psychiatry 7(Suppl 1): S71-S80.

Lister RG (1987). The use of a plus-maze to measure anxiety in the mouse. Psychopharmacology (Berlin) 92: 180-185.

Lydiard RB (2003). The role of GABA in anxiety disorders. J Clin Psychiatry 64(Suppl 3): 21-27.

Mathis C, Paul SM, Crawley JN (1994). Characterization of benzodiazepine-sensitive behaviors in the $\mathrm{A} / \mathrm{J}$ and $\mathrm{C} 57 \mathrm{BL} / 6 \mathrm{~J}$ inbred strains of mice. Behav Genet 24: 171-180.

Mikkelsen JD, Soderman A, Kiss A, Mirza N (2005). Effects of benzodiazepines receptor agonists on the hypothalamic-pituitary-adrenocortical axis. Eur J Pharmacol 519: 223-230.

Nielsen EB, Suzdak PD, Andersen KE, Knutsen LJ, Sonnewald U, Braestrup C (1991). Characterization of tiagabine (NO-328), a new potent and selective GABA uptake inhibitor. Eur $J$ Pharmacol 196: 257-266.

Porsolt RD (2000). Animal models of depression: utility for transgenic research. Rev Neurosci 11: 53-58.
Porsolt RD, Bertin A, Jalfre M (1977a). Behavioral despair in mice: a primary screening test for antidepressants. Arch Int Pharmacodyn Ther 229: 327-336.

Porsolt RD, Le Pichon M, Jalfre M (1977b). Depression: a new animal model sensitive to antidepressant treatments. Nature 266: 730-732.

Radian R, Ottersen OP, Storm-Mathisen J, Castel M, Kanner BI (1990). Immunocytochemical localization of the GABA transporter in rat brain. J Neurosci 10: 1319-1330.

Rekling JC, Jahnsen H, Mosfeldt Laursen A (1990). The effect of two lipophilic gamma-aminobutyric acid uptake blockers in CA1 of the rat hippocampal slice. Br J Pharmacol 99: 103-106.

Sayin U, Purali N, Ozkan T, Altug T, Buyukdevrim S (1992). Vigabatrin has an anxiolytic effect in the elevated plus-maze test of anxiety. Pharmacol Biochem Behav 43: 529-535.

Schaller JL, Thomas J, Rawlings D (2004). Low-dose tiagabine effectiveness in anxiety disorders. Med Gen Med 6: 8.

Schmitt U, Hiemke C (1999). Effects of GABA-transporter (GAT) inhibitors on rat behaviour in open-field and elevated plusmaze. Behav Pharmacol 10: 131-137.

Seckl JR, Campbell JC, Edwards CR, Christie JE, Whalley LJ, Goodwin GM et al (1990). Diurnal variation of plasma corticosterone in depression. Psychoneuroendocrinology 15: 485-488.

Shepherd JK, Grewal SS, Fletcher A, Bill DJ, Dourish CT (1994). Behavioural and pharmacological characterisation of the elevated 'zero-maze' as an animal model of anxiety. Psychopharmacology (Berlin) 116: 56-64.

Smith GW, Aubry JM, Dellu F, Contarino A, Bilezikjian LM, Gold LH et al (1998). Corticotropin releasing factor receptor 1-deficient mice display decreased anxiety, impaired stress response, and aberrant neuroendocrine development. Neuron 20: 1093-1102.

Steru L, Chermat R, Thierry B, Mico JA, Lenegre A, Steru M et al (1987). The automated tail suspension test: a computerized device which differentiates psychotropic drugs. Prog Neuropsychopharmacol Biol Psychiatry 11: 659-671.

Steru L, Chermat R, Thierry B, Simon P (1985). The tail suspension test: a new method for screening antidepressants in mice. Psychopharmacology (Berlin) 85: 367-370.

Strickland PL, Deakin JF, Percival C, Dixon J, Gater RA, Goldberg DP (2002). Bio-social origins of depression in the community. Interactions between social adversity, cortisol and serotonin neurotransmission. Br J Psychiatry 180: 168-173.

Takahashi LK, Kalin NH, Vanden Burgt JA, Sherman JE (1989). Corticotropin-releasing factor modulates defensive-withdrawal and exploratory behavior in rats. Behav Neurosci 103: 648-654.

Tao R, Auerbach SB (2000). Regulation of serotonin release by GABA and excitatory amino acids. J Psychopharmacol 14: 100-113.

Tsang SY, Xue H (2004). Development of effective therapeutics targeting the GABAA receptor: naturally occurring alternatives. Curr Pharm Des 10: 1035-1044.

Urani A, Chourbaji S, Gass P (2005). Mutant mouse models of depression: candidate genes and current mouse lines. Neurosci Biobehav Rev 29: 805-828.

Wolkowitz OM, Reus VI, Chan T, Manfredi F, Raum W, Johnson R et al (1999). Antiglucocorticoid treatment of depression: doubleblind ketoconazole. Biol Psychiatry 45: 1070-1074.

Wolkowitz OM, Reus VI, Manfredi F, Ingbar J, Brizendine L, Weingartner $H$ (1993). Ketoconazole administration in hypercortisolemic depression. Am J Psychiatry 150: 810-812. 